\title{
Persuasion as a function of varying amounts of distraction
}

Ss in four conditions heard the same communication. No slides were shown in a nondistraction condition; irrelevant slides shown in one condition were intended to be moderately distracting, and those in the others to be strongly distracting. Significantly more persuasion occurred in the moderate distraction condition than in the nondistraction condition and in one strong distraction condition. Suspicion of persuasive intent was greater for nondistracted $S$ s.

Festinger \& Maccoby (1964) demonstrated that a persuasive communication can be more effective if the audience is somewhat distracted from the communication. The effect seems to have been a reliable one, although it was found in only two of three populations studied and only for Ss who were strongly opposed to the position advocated. Freedman \& Sears (1965) found no significant effect of distraction, but their distraction was a weak one, consisting only of misleading instructions preceding a persuasive communication.

While moderate distraction may produce greater persuasion, might strong distraction reduce persuasion? (1) In comparison with moderate distraction, strong distraction should make it more difficult for the audience to comprehend a persuasive message, thus making it less likely that a basic point or a compelling sequence of arguments is comprehended. (2) It may be frustrating to have attention and comprehension made difficult. If the communicator or the experimenter, who in some sense is the communicator's sponsor, is perceived as the source of distraction, audience members might react by rejecting the communication independently of the apparent validity of its assertions. (3) Strong distraction might make the experiment seem ludicrous, leading Ss to reject the communication or the speaker as not worth serious consideration.

Festinger and Maccoby assert that distraction enhances persuasion because it makes it difficult for people to think of counterarguments. An alternative interpretation is that audience members do not attempt counterarguments because distraction disguises the experiment as one on comprehension; consequently, suspicion of persuasive attempt is not aroused.

The present study was designed to test the hypothesis that there is a curvilinear relation between distraction and persuasion and to investigate the relation of suspicion of persuasive intent to distraction.

\section{Method}

There were four conditions in the experiment, which used a posttest-only design. Ss heard a tape-recorded communication, preceded by instructions to expect to evaluate the communication after hearing it. In three of the conditions Ss saw slides accompanying the talk. In the fourth, a projector illuminated the screen, but no slide was shown. In each of the three conditions that used slides, there were six slides, and the slides were changed at exactly the same points during the talk.

The communication used was one advocating opposition to tuberculosis chest $\mathrm{X}$-ray surveys, a position at great variance from opinions reported in a survey of persons from the same population as the Ss of the present experiment. The condition in which no slides were shown was intended to be a nondistraction condition. There was a moderate distraction condition and two strong distraction conditions. Distraction was manipulated through varying the oddity of the irrelevant (to the communication content) scenes depicted; i.e., the slides in the moderate distraction condition were intended to be less unusual than the slides in either of the strong distraction conditions. The slides in the moderate distraction condition and in one of the two strong distraction conditions were relevant to dental hygiene. The slides in the other strong distraction condition were a heterogeneous set of illustrations for a general psychology course.

The first postmeasure questions asked Ss to evaluate the talk and report their reactions to it. There followed a 10-item, Likert-scored postmeasure of attitudes, justified by a statement that information on attitudes was necessary for the interpretation of evaluations. Following the posttest were open-ended questions asking for reactions to the experiment and for statements of the purpose of the experiment, the position advocated, and the arguments given in support of the position advocated.

Ss were 67 undergraduates, run in groups of five to nine.

\section{Results}

The posttest mean for each treatment group is presented in Table 1 , as are means for ease of paying attention, suspicion of persuasive intent, accuracy in stating position advocated, and adequacy of recall of arguments.

Partial success in manipulation of distraction comes from data showing that $\mathrm{Ss}$ in each distraction condition reported significantly less ease of paying attention to the spoken material than Ss in the nondistraction condition (lowest $t=1.91, \mathrm{df}=27, \mathrm{p}<.05$ ). Although $\mathrm{Ss}$ in the two strong distraction conditions reported slightly less ease of paying attention than did the Ss in the moderate distraction condition, the differences are not significant. 
Table 1. Means of Postmeasures

\begin{tabular}{lcccc} 
Measure & None & Moderate & $\begin{array}{c}\text { Strong: } \\
\text { dental } \\
\text { slides }\end{array}$ & $\begin{array}{c}\text { Strong: } \\
\text { psychology } \\
\text { slides }\end{array}$ \\
\hline $\begin{array}{c}\text { Posttest of attitudes } \\
\text { Ease of paying atten- } \\
\text { tion }\end{array}$ & 3.69 & $5.77^{a}$ & 5.09 & $4.13^{b}$ \\
$\begin{array}{c}\text { Suspicion of per- } \\
\text { suasive intent }\end{array}$ & 1.75 & $1.23^{a}$ & $1.14^{a}$ & $1.19^{a}$ \\
$\begin{array}{c}\text { Accuracy in stating } \\
\text { point of talk }\end{array}$ & 1.88 & $0.62^{a}$ & $1.05^{a}$ & $0.56^{a}$ \\
$\begin{array}{c}\text { Adequacy of recall } \\
\text { of arguments }\end{array}$ & 1.88 & 1.46 & 1.68 & $1.31^{a}$ \\
\begin{tabular}{c} 
Number of Ss \\
\hline
\end{tabular} & 16 & 13 & 22 & 16 \\
\hline
\end{tabular}

Note-Means marked with a are significantly different from the comparable nondistraction mean; the one marked with $b$ is significantly different from the comparable moderate distraction mean.

It had been predicted that moderate distraction would produce more persuasion than nondistraction and strong distraction. The moderate distraction condition produced posttest attitudes significantly more in the direction advocated than the nondistraction condition $(t=2.18, d f=27, p<.025)$ and the strong distraction condition using psychology slides $(t=1.89, d f=27$, $p<.05)$. The difference between the moderate distraction condition and the strong distraction condition using dental hygiene slides was in the predicted direction but not significant.

Every one of the distraction conditions produced significantly less suspicion of persuasive intent than did the nondistraction condition (lowest $t=1.68, \mathrm{df}=36$, $p<.05)$. By far the most common alternative purpose Ss in the distraction conditions gave for the experiment was that it was a study of comprehension in the presence of distraction.
Recall data did not differentiate among distraction conditions and showed virtually no differentiation of nondistraction from distraction.

\section{Discussion}

The data reported here provide the first strong demonstration that moderate distraction facilitates persuasion. They also provide some support for the hypothesis that moderate distraction produces more persuasion than strong distraction. The suspicion data suggest that moderately distracted Ss may be more prone to be persuaded because they are less inclined to suspect that persuasion is intended, but the suspicion data cannot account for the significant difference in persuasion between moderate distraction and one of the two strong distraction conditions. Moreover, since suspicion was assessed after the end of the persuasive communication and since the question assessing it may have been the first stimulus to suspicion, no conclusive statement can be made about the relative primacy of occurrence of suspicion and other defensive reactions. For example, it is possible that a search for counterarguments leads to suspicion of persuasive intent rather than the reverse being the case. Assuming that there really is a curvilinear relation between distraction and persuasion, one possible explanation of the relation is that distraction decreases suspicion, thus facilitating persuasion, but larger amounts of distraction lead to rejection of the communication and the communicator as ridiculous.

\section{References}

Festinger, L., \& Maccoby, $\mathbf{N}$. On resistance to persuasive communications. J. abnorm. soc. Psychol., 1964, 68, 359-366. Freedman, J. L., \& Sears, D. O. Warning, distraction, and resistance to influence. J. pers. soc. Psychol., 1965, 1, 262-266.

\section{Erratum}

Hoats, D. L.\& Gerjuoy, Irma R. Associative symmetry with two conditions of perceptual organization. Psychon. Sci., 1966, 4 (10), 341-342,-Figure 1 was printed incorrectly. It should be rotated $90^{\circ}$ counterclockwise. 